This item was submitted to Loughborough's Research Repository by the author.

Items in Figshare are protected by copyright, with all rights reserved, unless otherwise indicated.

\title{
Troubles with assessments in gifting occasions
}

PLEASE CITE THE PUBLISHED VERSION

http://dx.doi.org/10.1177/1461445612457490

\section{PUBLISHER}

(c) The Authors. Published by SAGE Publications

\section{VERSION}

VoR (Version of Record)

\section{PUBLISHER STATEMENT}

This work is made available according to the conditions of the Creative Commons Attribution-NonCommercialNoDerivatives 4.0 International (CC BY-NC-ND 4.0) licence. Full details of this licence are available at: https://creativecommons.org/licenses/by-nc-nd/4.0/

\section{LICENCE}

CC BY-NC-ND 4.0

\section{REPOSITORY RECORD}

Robles, Jessica. 2019. "Troubles with Assessments in Gifting Occasions”. figshare. https://hdl.handle.net/2134/20526. 


\title{
COVER PAGE
}

\section{Paper for DISCOURSE STUDIES}

Full title: Troubles with assessments in gifting occasions v.3: 3 July 2012

Author: Jessica S. Robles

Short title: Assessments in Gifting

Size: 10,190 words, $9.62 \mathrm{MB}$

\author{
Jessica S. Robles \\ Institutional details: \\ University of New Hampshire \\ Department of Communication \\ Horton Social Science Center, 20 Academic Way \\ Durham, NH 03824 \\ Jessica.robles@unh.edu \\ Office: (603) 862-3315 \\ Fax: (603) 862-1913 \\ Personal details: \\ 5 Meaderboro Road \\ Rochester, NH 03867 \\ Jessica.s.robles@gmail.com \\ (707) 853-3181
}




\begin{abstract}
This paper analyzes gift-exchange occasions as both a sequentially organized activity, and as a ritual practice imbued with social and cultural meaning. Specifically, the paper focuses on the role of assessments in gifting sequences, the distribution of assessments across participants, and some of the possible troubles which can arise in doing assessments of gifts based on discourse analysis of 44 gifting situations in one family's 30 home videos spanning 13 years. I argue that participants encounter difficulties in the process of proffering assessments of gifts, and that such troubles revolve around the dilemma of constructing positive assessments as authentically given. The analysis discusses the organization of action in gifting occasions, outlines the expectations and dilemmas involved in doing assessments of gifts, and presents participants’ discursive practices for managing potential troubles in gift assessment.
\end{abstract}

\title{
Key words
}

Gifting, discourse analysis, ritual, morality, assessments, authenticity, alignment, communication dilemmas 
Bio note: Jessica S. Robles (PhD, University of Colorado at Boulder) is a lecturer at the University of New Hampshire. Her research looks at discursive and embodied communicative practices, particularly with regard to morality, trouble and conflict, in various institutional, interpersonal, and cultural contexts. 


\section{Troubles with assessments in gifting occasions}

The giving and receiving of gifts is a practice which is both ordinary and special, one with its own cultural, social, and relational expectations. Occasions for gift exchange are organized and orderly, yet fraught with assumptions and face demands. This paper analyzes giftexchange occasions as a sequentially organized activity and as a ritual practice imbued with social and cultural meaning. The paper focuses on the role of assessments in gifting sequences, the distribution of assessments across participants, and some of the possible troubles which can arise in doing assessments of gifts. Based on discourse analysis of 44 gifting situations in a collection of one family's 30 home videos spanning 13 years, I argue that gift recipients, givers and onlookers encounter difficulties in the process of proffering assessments of gifts. These include interactional dilemmas, involving choices in what to say and how to say it, as well as sequential concerns with the placement and production of assessments. The care with which assessments are collaboratively constructed, and the trouble participants may confront doing so, indicate an ideal of authenticity which underlies gifting occasions and which is at odds with the social expectation that gifts must be assessed positively.

The next section covers the site of the gift-exchange occasion as a ritual practice and a sequentially organized activity, then reviews assessment as central to gifting. The section thereafter outlines the methodological approach, then presents the analysis of examples from 44 giftings, beginning with the sequential actions involved and in particular discussing the nature of assessments. The analysis focuses on some of the possible troubles involved in making assessments during gifting situations, and techniques participants employ for dealing with those troubles. The final section summarizes this work, discusses some implication and limitations of the analysis, and offers directions for future research.

\section{Gift exchanges as communicative events}

Gift exchanges occur in many areas of life-they happen regularly, across different cultural contexts. Gift-exchanging is both an ordinary, and a special occurrence. It is ubiquitous and taken as a normal feature of everyday life, but is also associated with fairly formal, scripted, 
ceremonial situations. Gift exchanges are what Craig (2006) calls a practice-a recognizable activity governed by particular expectations and involving particular ideals of how to do it well. As such, the occasion of gifting constitutes a communicative event, an organized situation constructed through talk and other symbolic actions which accomplish the gift-giving and giftreceiving acts for doing the occasion.

Gift-giving and gift-receiving are practices which do not correspond tightly to utterancelevel actions. The gift exchange occasion is complex and involves multiple participant moves. Jointly producing an event-level activity of this nature requires a confluence of what Hua, Wei and Yuan (2000) analyze in terms of "holism,” the cultural and situational features and expectations of the event, and "emergence," the sequentially-organized means by which the event is locally accomplished. The following sections begin first with a review of gifting as ritual, social and cultural. The section thereafter looks at the ways in which gift exchanges are produced turn-by-turn in interaction. The last section focuses particularly on assessments, one sort of action type which organizes the central activity of gift-openings and which is the focus of analysis in this paper.

\section{The ritual of gift exchanges}

Gifting is a ritual practice, a culturally-contexted activity for achieving social purposes beyond that which appear to be obvious. Like communication in general, gifting has a form which has social consequences and patterned meanings through which participants construct reality and create community. Ritual involves participation in "serious life," in moments which are “morally freighted” with right or wrong ways to act (Rothenbuhler, 2006: 13). Though ostensibly gift exchanges are for giving presents as a way of celebrating something, their social and cultural functions go much deeper. Gift exchanges are about building, maintaining and displaying relationships with others, and are bound by, as well as enacting of, cultural moral ideologies. This section discusses gift exchanges as a morally implicative ritual with social and relational expectations. 
Gift exchanges can be thought of as a particular sort of "definition of the situation." Drawing on Goffman $(1959,1967,1974)$, to participate in gift exchanges involves being able to fit into the situation and take the appropriate line for how to interact with others in the scene. Giving and receiving gifts requires managing the positive identity of one's own face as, say, a gift-giver, as well as the face of the gift-receiver. One must perform the expected identities of "being gracious" and "being appreciative.” Part this performance is expected to occur through what Goffman (1981) calls “response cries.” Because gifts are often meant to be surprises (hence the wrapping) in formal gifting occasions, it is expected that upon first viewing, the gift-recipient will emit some sort of "natural" immediate response, though oftentimes, once the gift is visible to all, response cries will be choral.

As Hua, Wei and Yuan (2000) note, gift offerings and acceptances are not just a communicative event, but a politeness event. Gifting is also culturally shaped. Hua et al. analyze gift offering and acceptance in Chinese contexts, arguing that the unique Chinese meaning of the word "gift" does not have the same sense or expectations as is involved in U.S. notions of "politeness." The gifting situations Hua et al. analyze are unique also because they are often oneto-one, are not part of a larger "gift-opening scene," and more often involve money and unwrapped gifts. Furthermore, Hua et al. note that there is a strong tendency in Chinese gifting to downplay the importance of, or even denigrate, the gift.

Part of what makes gift-exchange occasions ritualistic in nature is that they have cultural norms or rules which guide how they are expected to unfold. This is experienced by participants as normal gifting. Areni, Kiecker and Palan (1998) note that it is typical or at least assumed that some amount of thought has gone into gift acquisitions. Gifts may symbolize the relationship, refer to shared history, indicate knowledge of preferences, seem useful, or respond to a particular need. Gifting is a "conscious" U.S. practice in that there is presumed to be considerable work exerted to acquire appropriate gifts, plan and arrange the gift-exchange occasion (where it will happen, when, who will be there), and coordinate associated items and activities (food or cake, for example) (Belk, 1988; Camerer, 1988). A number of rules are involved: one must not give 
someone a gift that someone else has already gotten for the recipient; one must give gifts to others which appear roughly similar in value to those received; gifts are often supposed to be "personal” (demonstrating a relationship) rather than "impersonal” (giving things like money or gift cards are often done in addition to other wrapped gifts); gifts must be reacted to positively no matter how the gift-recipient feels about them (Cheal, 1986).

Giftings are moral; they constitute local ideologies of how to demonstrate goodwill and appreciation of others, and are ways of achieving a shared sense of how to be a good person to others. There are obligatory and expected ways of participating in gifting occasions, and social consequences for violating them. As Bergmann (1998) describes, one way of viewing morality in discourse is by looking at how moral concepts and values are taken up in, and guiding of, interaction. Morality is at work in gifting through the implications gifting has for people's identities and relationships. Participants are responsible for working together to construct the gifting occasion in the culturally and socially appropriate manner. This "working together” is discursive — through talk and other symbolic resources, participants organize (and are organized by) the situation of exchanging gifts. Gift exchanges are thus not just social, cultural or relational, but are also emergent, constructed turn-by-turn in interaction. It is this aspect of gift exchange to which I turn next.

\section{The sequentially-organized features of gift exchanges}

Gifting is a practice made up of a recognizable, organized form. Like any activitygreetings, invitations, shopping, gossip_-gift exchanges are locally produced in interaction. The orderliness of gift exchanges is accomplished through the sequential actions which build its character. This section discusses the conversation analytic approach to gift exchanges which sees them as sequentially-organized.

Hua, Wei and Yuan (2000), in addition to looking at gifting as a unique cultural phenomenon in Chinese gift offers and acceptances, also analyze how gift exchanging is sequentially organized in talk. The authors note distinct sequential stages of gift-giving and attendant expectations involved. For example, in their analysis, only a small number of gift 
offers were "unmarked," with the offering being already expected within the structure of this situation. This is different from the instances analyzed in the current study, which looks at situations already defined as "gifting” occasions, and in a U.S. context, where talking-down the gift appears not to be expected. Furthermore, such marking with explanations and comments on the gift were done before the acceptance phase, almost as a disclaimer, in Hua et al's study, whereas in the current analysis, accounts for the gift usually occurred after the gift was "seeable" to the recipient and others.

In Good and Beach's (2005) conversation analytic study of birthday parties as situated action, they note that gift exchanges are ritual in nature, meant to commemorate important events and celebrate and appreciate particular people and their lives. Gifts themselves are communicative objects, symbolizing something about the gift-giver, the gift-recipient, and their relationship. Activity-specific identities such as gift-giver and gift-recipient organize the actions and participation expected of the occasion. Good and Beach analyze openings or initiations, which commonly begin as a summons-answer presequence for securing the attention of particular others before the gift can be proffered or pointed out for opening. The authors also look at how assessments manage the gift opening sequence throughout the situation.

Assessments are an important action within the sequential organization of gift exchange occasions. As Good and Beach (2005) point out, gifts are assessable objects. In a sense, assessments are the second pair part to the gift itself. This indicates the importance of looking at embodied interaction and objects in interaction, since the gift itself can almost be analyzed as its own turn. Because assessments are so important as a sequential feature of gift exchanges, the ensuing analysis focuses on how assessments are done, and some troubles that can arise in their production.

\section{Assessments and gifts}

Assessment is a major part of gift occasions. “Assessments” are actions which espouse a stance or evaluation. Responses to assessments often take the form of an agreement or disagreement with the assessment, plus a further assessment: for example, “well, it was fun 
Claire”/ "yeah, I enjoyed every minute of it.” Assessments are produced with the concomitant unspoken claim that the speaker has some knowledge of the assessable (Pomerantz, 1984). Assessments can themselves be preferred or not, and can be responded to in a preferred or dispreferred format. Assessments accomplish particular interactional jobs and can occur in brief instances or extended packages; and participants treat assessments as projected social actions. As relevant to participation frameworks, assessments construct and enact shared experiences and collective affect. Assessments can be accomplished through a number of symbolic actions, including explicit talk, but also though facial expressions, gestures, and other means (Goodwin and Goodwin, 1987).

In gift-exchange occasions, assessments form an important activity in organizing the sequential actions of giving and receiving a gift. When a gift is proffered, its action as beinggiven makes it an assessable object. "Reacting” to a gift is a strongly preferred and socially expected action. If a gift is opened and no one (neither the opener nor onlookers) reacts, it would be seen as a noticeable absence-and not as communicating “no reaction,” but in fact as communicating a negative reaction. Because the gift-giving has a sort of sacrifice or generosity built into to it (similarly to an invitation or compliment), to respond negatively is to provide an unfit response given the action. That positive reactions are preferred is partly evinced by reactions to their lack (either "no reaction" or an actual negative one), and by the unmarked nature of positive responses. Such responses may take the form of verbal assessments, but also response cries, facial expressions, gestures, smiles, etc. (Good and Beach, 2005).

The "knowledge" of the assessable gift is unevenly distributed at different sequential moments of a gifting occasion. In the beginning, before a gift is unwrapped, only the gift-giver knows for sure what the gift is, most of the time. This is why the gift is knowable and assessable, for the most part, once it has been opened. The viewing of the gift makes assessment relevant by the opener/gift-recipient, and display of the gift for others (or the viewing of the gift by those close enough to see it) makes it assessable to the audience of other participants. Between the opening and the setting aside of the gift, assessments carry the major action of the core of gifting 
situations. Though gifts can be quite private in nature, their displays in these situations are semipublic. The assessment is not shared only between gift-giver and recipient, but is viewed and participated in by others present; assessment is distributed among participants. The assessment will preferably be matched with aligning assessments and actions by the recipient in particular, and others in general (Lindström and Mondada, 2009). Assessments are morally implicative because they are socially and relationally consequential, dealing with the shared (or unshared) understandings and values assumed between gift-givers and recipients.

\section{An analysis of gifting occasions}

The analysis employed in this paper combines influences from action implicative discourse analysis (Tracy, 1995) and an embodied/multimodal/microethnographic style of conversation analysis (e.g., Fox, 1999; Goodwin, 2007; Heath 2002). Action implicative discourse analysis is a grounded practical theory (Craig and Tracy, 1995) approach to discourse analysis. Grounded practical theory is a perspective which analyzes communicative practice, investigates practical problems involved, reconstructs participants' techniques for dealing with those problems, and formulates what the situated ideals of the practice are which are guiding participants' interactional choices.

The action implicative discourse analysis employed herein looks at a particular practicegift exchanges — and seeks to investigate the problems it entails, the strategies through which participants seek to address those problems, and the situated ideals guiding the practice and its techniques. By employing this method, the analysis herein focuses on what about the gift exchange occasion is tricky or difficult, how and why participants encounter such problems, and in what practical ways techniques of the practice can be improved. However, this analysis also seeks to join this practical approach with a close description of sequentially-organized embodied actions, such as is employed in conversation analytic approaches. Conversation analytic approaches which look at actions accomplished not only in talk, but also through mobilization of other symbolic resources (gaze, gesture, object manipulation, spatial arrangement, etc.) treat 
myriad actions as contributing to the turn-by-turn organization of talk-in-interaction (e.g., Fox, 1999; Goodwin, 2007; Heath, 2002).

Together, these analytic approaches make a number of demands on the way in which particular communicative events are analyzed. On one hand, action implicative discourse analysis requires an in-depth ethnographic knowledge of the site or situation being analyzed. In the case of this analysis, such depth is obtained through the sheer number of video analyzed, and is partially supplemented by a personal knowledge of the participants in the setting. On the other hand, action implicative discourse analysis tends to study practices which are institutionally bound and therefore more explicitly nameable. This analysis, instead, looks at a non-institutional situation in casual family interactions; however, the practice of gift exchanges is a culturallyrecognizable activity with a particular "shape” which is accomplished in similar ways across particular families and occasion-types.

Furthermore, conversation analytic approaches insist that analysis focus on participantaccomplished actions and activities which can be empirically demonstrated as oriented to by participants. This analysis demonstrates actions as empirically visible by attending to all participant actions which are treated as meaningful and relevant by the participants to the occasion. Such actions include talk, nonverbal communication, and other symbolic actions and semiotic media. In addition to Jeffersonian-style transcription, some screenshots of video scenes have been inserted to show embodied practices.

The analysis which follows is broken down into two parts. The first section describes in detail the data and the practice being analyzed, offering a "prototype" of the gift-exchange occasion in these particular data which may be generalizable, or at least bear a family resemblance, to gift-exchange occasions in similar data. The second section then analyzes closely particular gift-exchange sequences, looking at moments in which sequential interactional choices invoke potential problems for participants. In this section, the goal is not only to characterize actions, but also to reconstruct the problems and techniques involved. Specifically, this analysis focuses on troubles and dilemmas involved in the actions of assessment which are a 
feature of gift-exchange occasions. According to Tracy and Ashcraft (2001), interactional dilemmas involve local choices in problematic situations in which there is no clear best conversational action. Gift exchanges in this analysis involved a dilemma between the ideals of giving assessment which were both positive and authentic.

\section{Analyzing gift-exchange sequences in home videos}

The data include 30 home movies, each one to two hours long, of a single set of extended family members ${ }^{1}$, recorded between 1987 and 2000. Gift-giving and receiving occur regularly across the videos, but this analysis focuses on occasions of gift exchange which are formally organized to be gifting occasions. There were 44 total analyzed gift-exchange sequences culled from the data. These featured two varieties of gift exchanging: unidirectional (birthdays, graduations and a return-from-travel) and omnidirectional (Christmas, and one particular “mass” birthday during which six family members' birthdays were celebrated at once). Participants in the videos included the central family (a mother and father, two older daughters, and two younger brothers) and their extended family (the mother's parents, brother, and sister-inlaw; and the father's parents, sister, and brother-in-law). Occasional participants include more distant great aunts, uncles, cousins, and family friends.

Within the varieties of gift exchange, there are constraints on the occasion which will be visibly produced in slightly different ways, and thus governed by slightly different expectations. Directionality (who is giving gifts to whom, e.g. one-to-many, many-to-one, many-to-many) affected how people were configured and what actions and participant roles they performed. Furthermore, almost all of the gifting occasions analyzed occurred within a special, overarching celebratory event (Christmas, birthdays). For this particular family, in these data, Christmases involved three gift-exchange occasions (Christmas Eve, Christmas morning, and Christmas afternoon) and birthdays involved between two and three occasions (the morning of the birthday, and one or more other occasions when the immediate family was joined by, or went to join, extended family members elsewhere). 
These constraints are structural to some extent, built into the features and expectations of the event. But there is another aspect of interaction which potentially governs gift-exchange occasions, and that is the age and relationship between participants. Birthday occasions in these videos only occurred for the children of the family (age 18 and younger) and not the adults. Children were the gift-recipients on Christmas mornings, and were not required to give gifts to adults. Children in these data were also not expected to open gifts one-at-a-time, always opened gifts first (during omnidirectional gift-giving), and often opened gifts together (even during one sibling's birthday, other siblings will help with the gifts, particularly for the youngest children). Finally, gift-giving to young children does not necessarily entail the same conversational rules as do gifts exchanged between adults (for instance, children are understood to sometimes need “prompting” to express thanks and may be forgiven for displaying less interest in clothing than in toys).

\section{The shape of gifting}

A gift-opening often begins with the initiation of a gift-exchange sequence, which can be opened in a number of ways. As Good and Beach (2005) describe, often an initiation involves a summons-response format. But these data rarely featured such explicit initiations. Instead, the beginning roughly corresponded to when everyone expected to be present was present (and at least partly attending). Sometimes there were only subtle attentional cues which directed gaze toward the opener and indicated that gift-opening was about to begin. Other times, there were more markings of gift-opening, but this was almost always with the youngest children and was never initiated by gift-openers. Excerpt 1 provides a typical example in which gift-opening happens with some indications of it being “time,” but no explicit verbal topical opening. The scene begins with Dennis, whose second birthday it is, entering the room, his mother following him with the camera.
Excerpt 1
Dennis: $\quad$ $\quad$ open it? o::pen it?
$2 \quad(2.0)$
$3 \quad$ Dennis: $\quad \mathrm{y} \uparrow$ eah
4 (25.0) ((background conversations, Dennis dances a bit, then sits)) 
Abraham: HEY IS EVERYBODY IN THE ROOM EVERYBODY'S IN THE ROOM=

Mike: $\quad$ =are you just about ready?=

Dennis: $\quad=$ YEAH ((screams))

Abraham: $\quad$ okay let's do it

Dennis begins by mentioning opening the gifts, though it is not clear whether he is requesting to open them, or is asking whether they are for him to open (his vocabulary and grammar are limited) (line 1); this is accompanied by pointing:

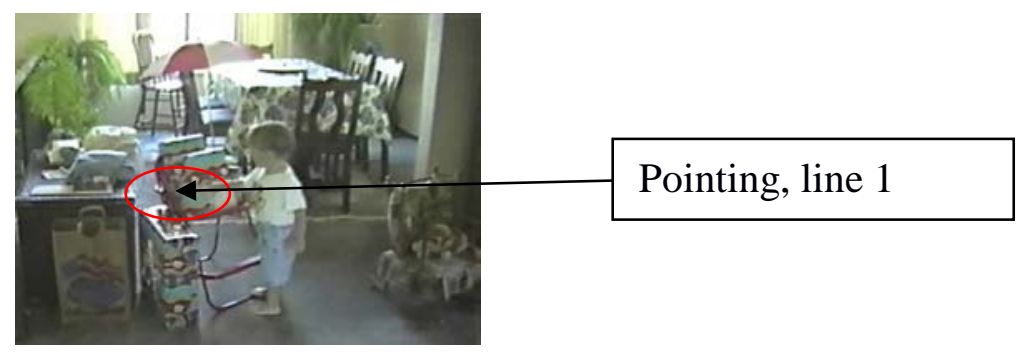

In either case, Jilly, his mother (who is behind the camera) does not reply and Dennis does not pursue it (line 2). He eventually sits down (line 4), but he sits next to his older sister, in the role of an onlooker, rather than by the gifts. Abraham is the one who signifies the pre-condition for gift-opening (that everyone is present, lines 5-6) and when Mike asks Dennis if he's ready (line 7), only then does Dennis seem to take up the role of the gift-opener, and he moves toward the presents. Abraham then makes explicit that the something is going to happen (line 9). But no one mentions or labels the event. Thus it seems that in gift-opening occasions, that the next main event is to open presents is largely unmarked.

Initiations of gift-exchanges are followed by an organization of the manner of gift opening and subsequently the unwrapping and displaying stage. Birthdays feature a pile of presents; the person whose birthday it is sits next to the presents on or near the ground, and is flanked by siblings who participate in admiring the gifts. Older siblings often permit younger ones to assist in unwrapping. The screenshots below show how siblings sit together by the gifts and participate in each other’s birthdays during unwrapping. 

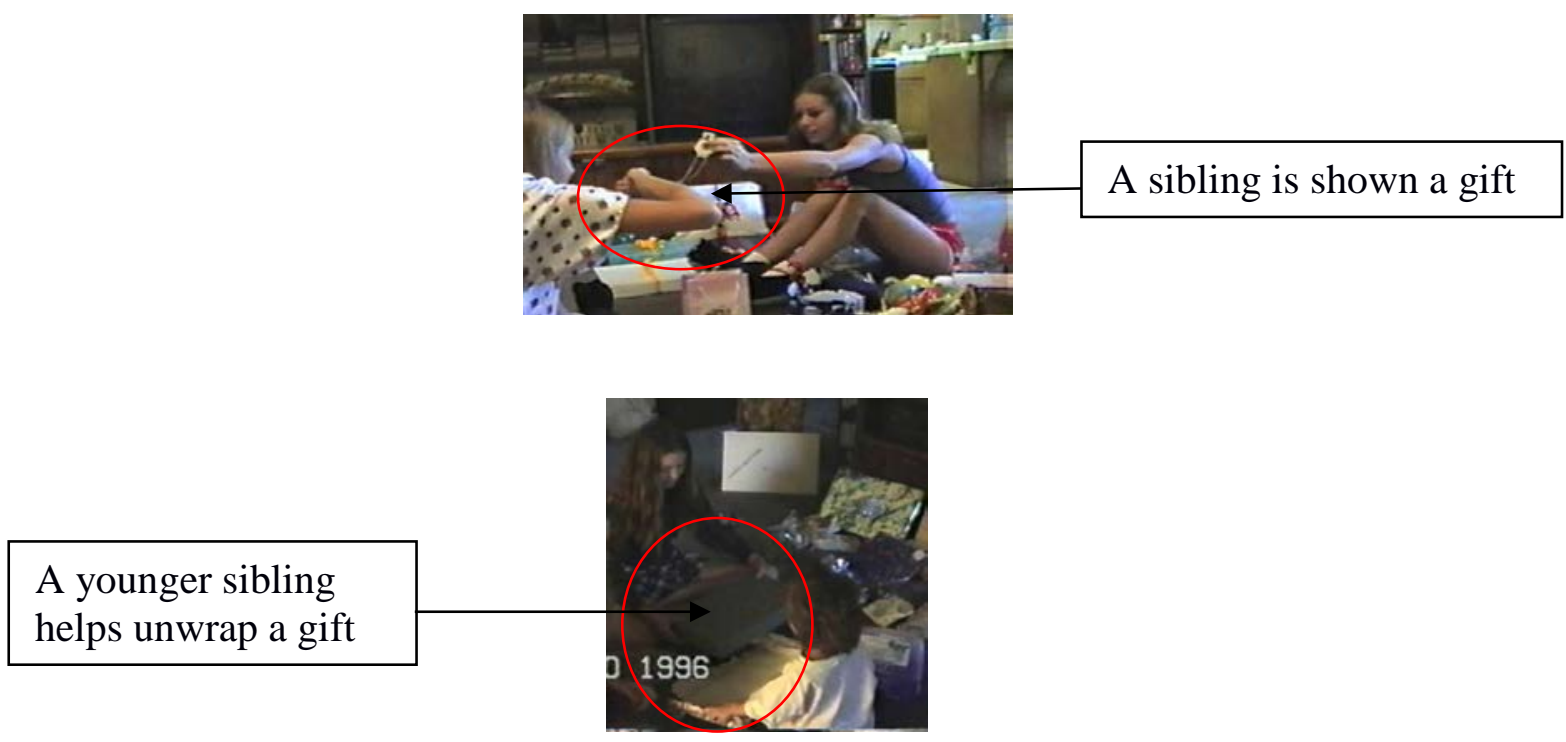

Other adults also often assist with or open gifts for young child recipients, as in excerpt 2 and the screenshot below it.

\section{Excerpt 2}

18 Abraham: Grampa ny个o:w open that one

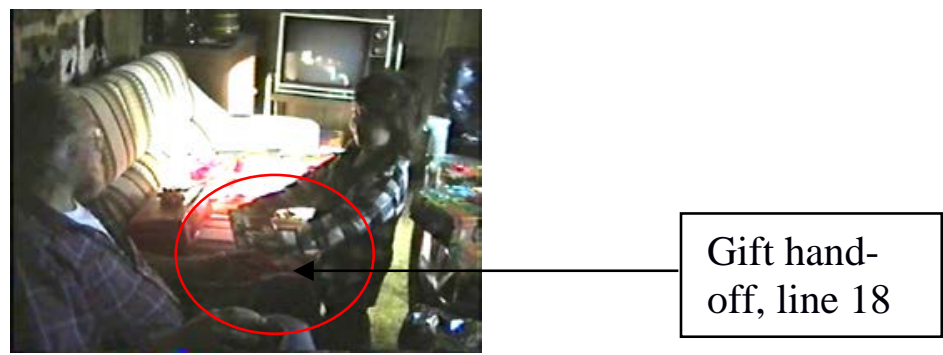

Christmases are organized similarly to birthdays in the case of the Christmas Morning occasion, but during the other two Christmas formats, are done in two stages. The first stage is like birthdays and Christmas mornings, and features just the children, opening gifts roughly at the same time. During the second stage, the children pass gifts around to the adults, who usually open them one at a time. The next screen shot, for example, shows a typical arrangement for Christmas Eve during which the children open their gifts first, seated together. The older children usually help the youngest with theirs first. 


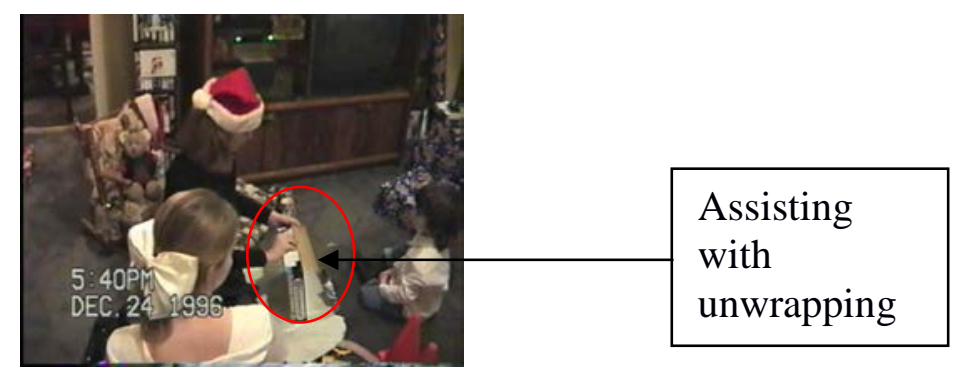

After the children open gifts, the remaining gifts are distributed to the adults by the children. This constitutes another sort of opening phase during which gifts are passed off (rather than "picked up” from a pile). This stage itself features a number of typical actions. The actual proffering of the gift, for instance, almost always is thanked by the gift-recipient, in gratitude for the passing rather than for the gift itself (since gifts are not always handed over by the original gift-purchaser). This can be a very short or an extended sequence involving inserted sequences not directly relevant to the gift-exchange. During the actual opening of the gift, other conversations may be going on (which are relevant or not to the gift itself), or conversation may be suspended.

During the unwrapping phase the gift-opener verbally signals their recognition of the gift, usually in an appreciative format, usually done in the form of a response cry or facial expression prior to verbal assessments; the gift-recipient then announces and/or displays the gift, which almost always involves holding the gift up, and is sometimes accomplished by siblings if the gift-recipient is quite young. It is during this phase that everyone has seen the gift and more explicit assessments can made, by the gift-recipient, onlookers, and even the gift-giver. Assessments of gifts can be short (consisting of as little as one turn) or multi-turn. It is assessments which are the focus of the following sections. First, however, the task remains to go through the closing actions of the occasion.

The closing of the gift-opening occurs differently depending on whether someone is the only person opening gifts in quick succession (during birthdays, and when children-only are opening gifts) or if many people are opening gifts one-after-another. In the case of the former, participants indicate by gaze, intonation and a “closing” gesture (folding the gift, putting it back in a box, setting it aside) that one is ready to move onto the next gift. In the case of the latter, 
similar actions occur, but the focal participant, and those attending, will signal a sort of "looking for" the next gift-opener. Gift-exchange occasions are "naturally" closed by the fact that, at some point, there will be no more gifts to open. Though during birthdays it is fairly obvious when there are no more gifts, during Christmas, there may be a show of "checking” for any possible gifts which were not noticed previously (perhaps hidden behind some low-hanging branches of a Christmas tree).

The next section focuses on the assessing actions which are made during the gifting occasion, and which usually begin once the gift-recipient displays recognition of the gift upon opening it (though assessments may also be given upon having been passed the gift, as when people make guesses as to something "good” being inside).

\section{Assessments in gifting}

Assessments can be made by anyone but are most strongly expected of the gift-recipient. The kinds of initial assessments expected of children are different from those expected of adults. Though children and adults are expected to some extent to perform "response cries" of delight upon opening a well-received gift, children are not necessarily expected never to perform response cries of dismay (though they may be sanctioned for doing so) whereas adults are never expected to do so, but rather are expected to be more explicit with formulating verbal comments assessing the gift and expressing gratitude toward the gift-giver.

Excerpt 3 and the screenshots below show a variety of embodied actions by Abraham as he guesses what is in the gift he is opening. His reactions are markedly not positive. In the first screenshot Abraham's tearing of the paper reveals a plain white box, usually of the type which contains clothing. He makes no facial reaction, and in the next shot his shoulders slump.

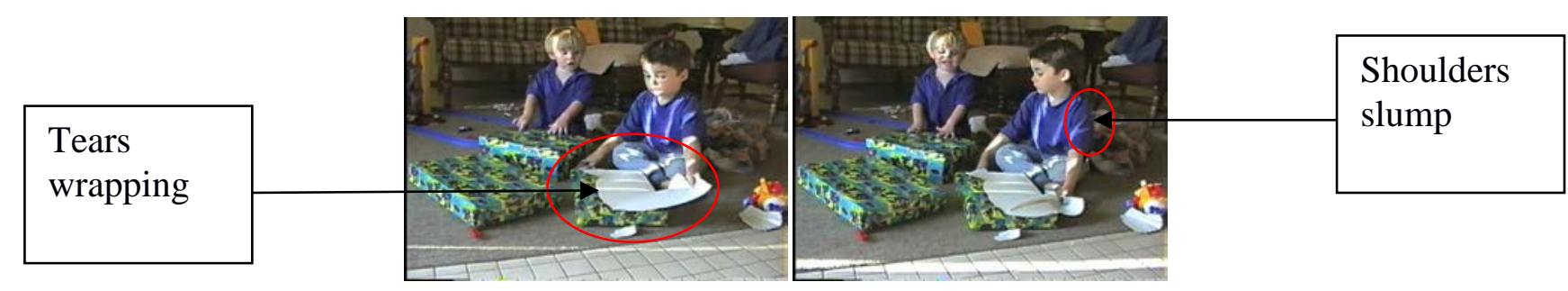


In the third screenshot, he make a dramatic gesture, putting his hand to his head, and says in a kind of parodied display “oh no!” indicating that clothes (“close”) are disappointing (line 37).

\section{Excerpt 3}

37

Abraham: oh no clo::se

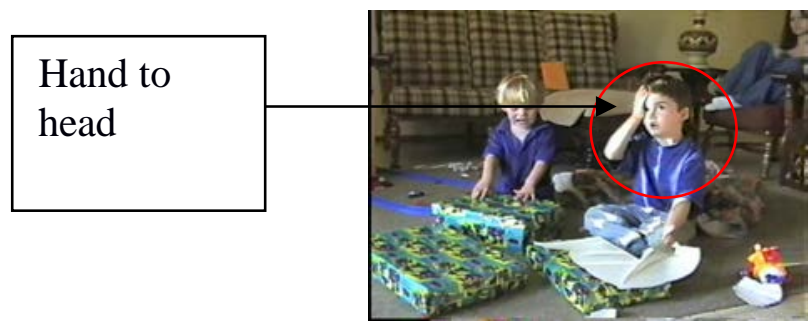

Excerpt 4 and the screen shots below it demonstrate more typical positive verbal and nonverbal responses. Overwhelmingly, intense and immediate displays of joy upon receiving a gift are unmarked. Excerpt 4 is an example of the intonational contours of an extreme positive assessment from a daughter upon receiving underwear. The response (line 39) is produced in an exaggerated, dramatic way, with exclamations, rising and falling intonation, and even vibrato (indicated by tildes).

\section{Excerpt 4}

$$
\text { J: } \quad \uparrow \text { oh wow- oh .hh wah } \sim 0 \sim 0 \sim \mathrm{W} \text { they're cyu: } \sim 0 \sim 0 \sim \text { te }
$$

The first screenshot shows nonverbal reaction from a grandmother receiving a key ring for her birthday. The ones below it show the second-youngest son (a year before the prior examples) reacting to a gift. The faces indicate expressions of delight and/or surprise: wide eyes, open mouths, or pursed lips:

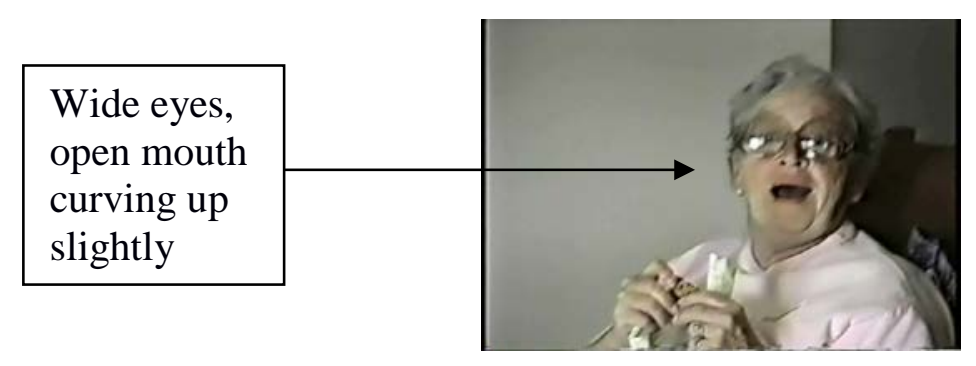




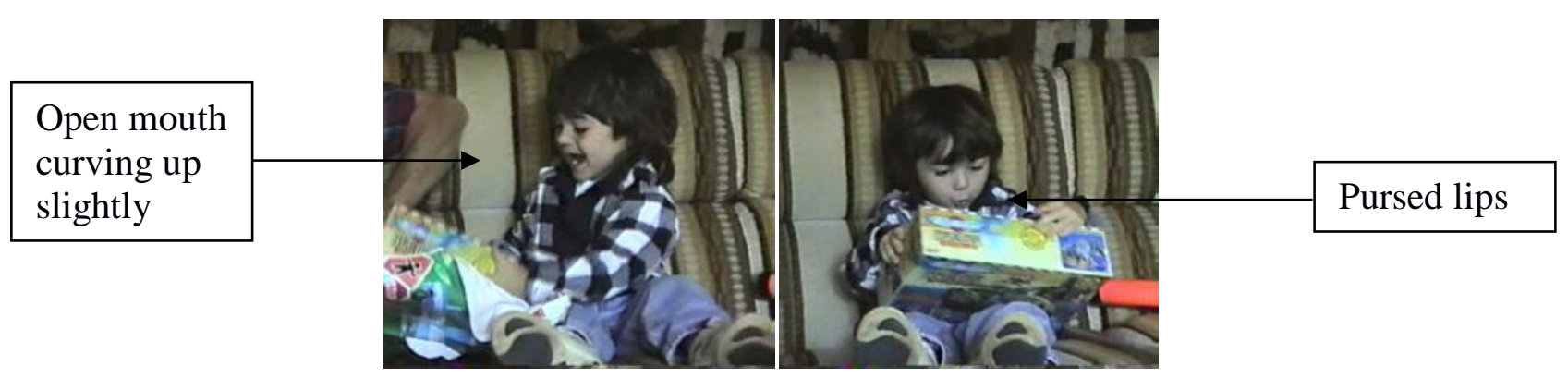

Excerpt 5 shows how jokingly negative verbal assessments can be mitigated by facial reactions.

\section{Excerpt 5}

Sam: o $\uparrow$ oh something she picked up off the side of the road

After commenting that the gift she received looks like something the gift-giver might have found on the ground (line 41), Sam shows it around smilingly (screenshot below) to indicate that she wasn't serious in her negative assessment of the gift, and her showing is met by appreciative response cries and positive assessments from the room.

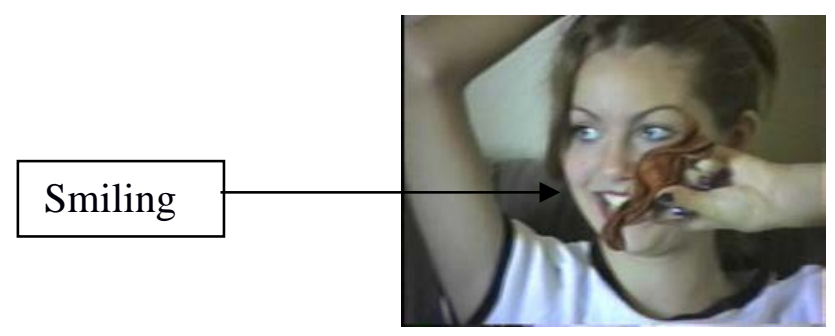

Assessments are often ratified by other participants. It is not unusual for response cries by the gift-recipient to be joined in chorus by response cries from onlookers, and formulated assessments may be matched by others as well. In excerpt 6 the assessment of "cute" is repeated (line 44) and matched (lines 45-46), then upgraded (line 47).

\section{Excerpt 6}

43

44

45

46

47

$$
\begin{array}{ll}
\text { Beatrice: } & \text { oh [my ga:wsh } \\
\text { Jilly: } & \quad \text { [lookit how cute] (.) super cute } \\
\text { (someone): } & \text { it's cyu::te }= \\
\text { Beatrice: } & =\text { =it's really cute }= \\
\text { Jilly: } & =\text { it's beautiful }
\end{array}
$$

The screenshot below shows four people gathered around the gift of the other, all "oohing” and "aahhing” and complimenting the gift, even touching it 


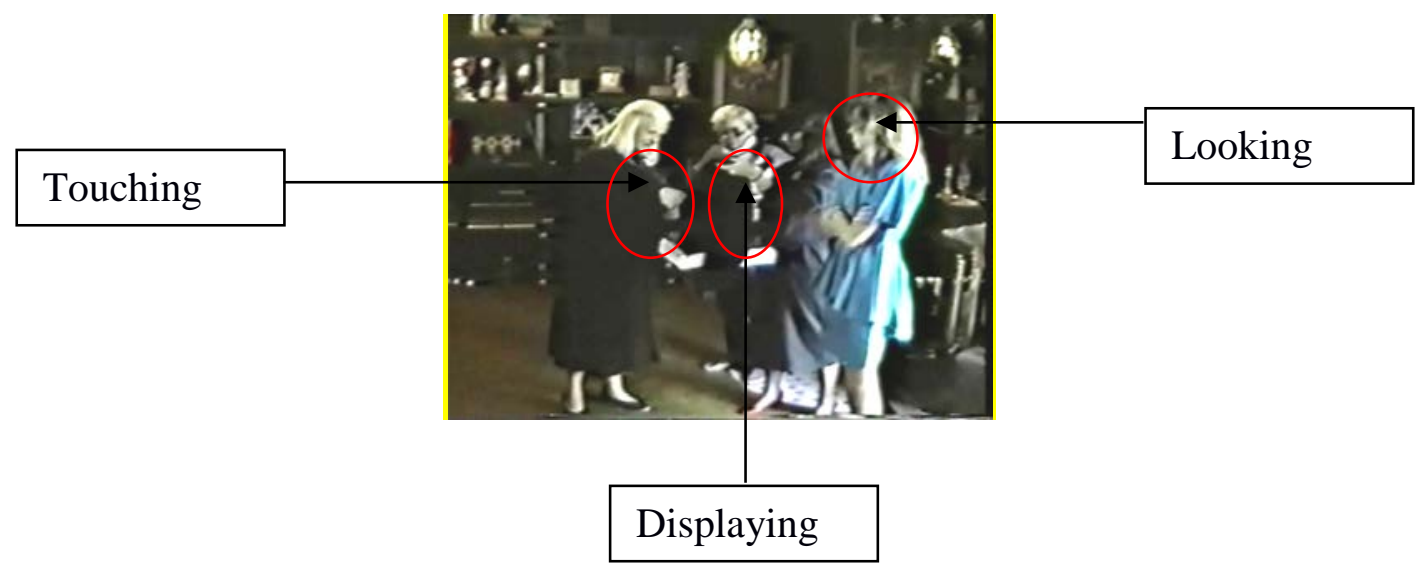

Assessments in this way are distributed across participants and negotiated jointly. Though the gift recipient is the focal assessor of the gift (and thus assessments from others may be reasonably seen as responses and as occurring under the aegis of slightly lower stakes), assessment nonetheless is worked out over the course of the activities occurring around a particular gift. Its ultimate assessment (and assessability) is not solely “owned” by the recipient.

Assessments make relevant particular actions by the gift-giver. Gift-giver responses to gift-recipient assessments may involve acknowledgement of gratitude (i.e. “you're welcome”), matching assessments (i.e. “it is nice, isn't it?”), or explanations of the gift (i.e. "I thought you would like that" or "I remembered you wanted one"). Sequences relevant to the gift-giver may also be opened by onlookers. Sometimes in the process of admiring a gift, an onlooker will prompt the gift-giver for an explanation of the gift, ask where the gift was obtained, or direct further assessments or gratitude regarding the gift toward the gift-giver "on behalf of" the gift recipient.

\section{Troubles with doing assessments}

Assessments both make visible possible troubles in gifting, but also are themselves part of how participants seek to attend to politeness, face, and relationships. Assessments during giftexchange occasions provide a means for participants to intersubjectively orient participant actions and identities toward a shared understanding of the gifting situation and of one another. Achieving this shared sense of the situation is morally implicative because there are not just actions to be done, but identities and relationships to be upheld. The following examples go through the most salient troubles of these particular data. These troubles arise because 
participants orient to an ideal of assessment which is inherently dilemmatic — that assessments be positive, but also authentic_-and techniques for producing assessments in preferred ways are delicately handled by recipients, givers and onlookers to attend to these contrasting demands.

\section{The obligation to positively assess gifts}

Gifting occasions display a preference for immediate, highly-positive assessments of a gift following the gift's opening. This demand is strongest for recipients, though it extends to all participants. Gift recipients overwhelmingly produce positive assessments without delay through extreme formulations, facial expressions, and responses cries meant to display joy at reception of the gifts; these assessments may be collaboratively produced across participants. The obligation to give a positive reaction and to avoid delaying it is indicated by the prevalence of most positive assessments dealing with superficial or obvious aspects of a gift such as its color or attractiveness. This strategy is a particularly "safe" way to praise a gift on one criterion even if others are undesirable, and means that a gift can begin being praised immediately (even before one knows precisely what it is or what it might be for). Excerpt 7 shows a typical example of this sort of assessment.

\section{Excerpt 7}

58 Beatrice: owell how cute (1.0) how cute ${ }^{\circ}=$

59 Jilly: =what did you get=

60 Beatrice: =a footstool

$61 \quad$ Jilly: oh that is cute (.) that's really cute

Though the first adjective that comes to mind regarding footstools is probably not their “cuteness,” here Beatrice and Jilly jointly construct cuteness (lines 58, 61) as the primary assessment. This is despite the fact that, whatever the footstool looks like, it is a functional rather than decorative gift. It is not clear why the function is not addressed here. Perhaps it is ambiguous to the participants why Beatrice got a footstool, or perhaps it contains implications about why Beatrice would need one (she is a grandmother, and older than most of the other participants). The footstool does have a flowered pattern, which was likely the first visible thing about it. In any case Beatrice begins immediately positively assessing the footstool on the basis of how it looks. 
Adults are expected to always give a positive assessment and to do so right away, but children are given more leeway on this, as demonstrated earlier. Children up to a certain age can delay assessment or even give negative assessments with little or no remonstration. There seems to be an assumption that children have not yet learned the rule of "always assess postively.” This also means that when they do provide a positive assessment, it carries more weight because it is assumed to be genuine. Excerpt 8 shows how a delayed nonverbal assessment which is positive is not treated as problematic. In this example, Abraham, who is less than two years old, opens a gift which turns out to be a stuffed animal. In reaction to seeing the gift, others present comment on it being “cute.” Abraham says nothing (there is not much he can say yet at this age), but after a couple seconds picks up the animal and hugs it several times, as shown below:

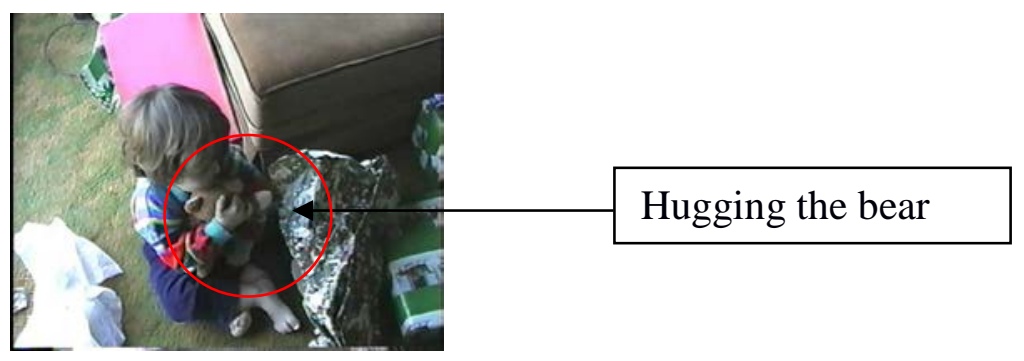

After the final hug (above), Jilly comments on his reaction as a genuinely positive one (line 76).

Excerpt 8 76 Jilly: I guess it passed the test

Part of why gift exchanges have implications for identities is because they are understood as ritual and semipublic "tests" of the gift-giver's knowledge of what the gift-recipient would want, like or need. This function of gift-giving is never commented on publicly unless the assessment is seen as sufficiently positive to risk it. In a different situation, such a comment would probably not be appropriate- if the gift were from Jilly, that would be one thing, but in fact the gift is from Jilly’s sister-in-law. To "name” the social function of a gift can be highly threatening, as threatening as it would be to make the comment "well you have to act like you like it, don't you?” to someone opening a gift (or saying “I guess it didn’t pass the test” if Abraham had thrown the bear aside). In this case, however, it seems okay because Abraham's reaction to the 
gift is taken as positive and genuine. This brings up the other horn of the dilemma around gift assessments: that they must not only be positive, but authentic.

\section{Some strategies for authenticating assessments}

Assessments of delight toward gifts and gratitude toward gift-givers must be displayed as "natural,” not artificial. Except perhaps for very young children, it is not the case that joyous response cries will do the trick by themselves, precisely because it is assumed that adults know that they have to give positive assessments and will do so regardless of how they really "feel" about a gift. Thus a more explicit assessment will almost always be made: the more detailed an assessment, the more convincing can be the sense that a gift is genuinely desirable.

An undelayed and unambiguously positive assessment (indeed, an exaggeratedly positive assessment) can lend a sense of authenticity in seeming spontaneous, but it is understood that enthusiasm can, and in gifting situations sometimes must, be faked. Giving detailed assessments becomes one way in which gifting participants do being convincingly and authentically “delighted"; but detailed assessments can also reveal an intersubjective mismatch between the expectations for the gift reception and its implications because unless a gift is "known" ahead of time, the gift is experienced (and often must be experienced) as a pleasurable surprise which is in some way aligned with the perceived effort put into the gift. In expanding assessments, participants invoke relational knowledge about the gift-recipient, situational appropriateness or functional necessity of the gift, and intentions of the gift-giver. In except 9 some of these are built into the assessment of a shirt by multiple participants, including the recipient, giver, and onlookers. Jack is the recipient, Jilly and Beatrice are onlookers on either side of him, and Bobby is the giver off camera.

\section{Excerpt 9}

62

63

64

65

66

67
Beatrice: $\quad$ perfect for Christmas [huh]

Jack:

Bobby: alright=

Jilly: $\quad=$ maybe you should go put that on [thank] you thank you 
68 Jack: $\quad$ very nice $=$

$69 \quad$ Bobby: =it's got that Scottish uh (.) that Scottish flair

$70 \quad$ Jack: right

In excerpt 9, Beatrice describes the shirt as “perfect for Christmas” (line 62), assessing its colors (a reddish plaid) favorably. Jack directs thanks toward the gift-giver (line 63), Bobby, who is offcamera and who acknowledges the thanks in the next turn (line 64). Jilly takes up Beatrice's initial assessment by suggesting Jack put the shirt on (since it has Christmas-y colors, and it's Christmas Day) (line 65), followed by laughter (line 66), indicating this is taken as a joke. Jack then comments again on the shirt in general as "nice” (line 68), and Bobby offers a further description of the shirt (line 69), which is ratified by Jack (line 70). Here is an instance in which ethnographic and personal knowledge is helpful. Jack is proud of his Scottish heritage, and often tells stories or gives information regarding his family past, his “clan” colors, recent books he’s read on Scotland, relatives he's learned about, etc. Thus, the fact that Bobby explicitly mentions the “Scottishness” is a way of emphasizing his knowledge of Jack and Jack’s preferences, and that "thought" went into purchasing the gift.

Though not as common as nonfunctional assessments, functional assessments nevertheless appear. Their status is uncertain, as they could be taken as less straightforwardly positive. Though calling a gift "nice” or "cute” may in some sense be a surface assessment, it is nonetheless more like a response cry, and thus coded positively so long as it is produced as though authentic. Functional assessments, on the other hand, could be taken as too detailed, too impersonal, or as “searching” to say something nice. Sometimes such possibilities are circumvented by others, either by commenting in detail on how useful the function of the gift will be (so that the gift-recipient need not state the obvious) or by joking about it. In excerpt 10, for example, a useful gift is accompanied by a joke delivered by the gift-giver.

Excerpt 10

$73 \quad$ Jim: ah uh (.) it's a desk lamp

$74 \quad$ Mike: y:eah (.) you know it also sends out a light to (.) UFOs

$75 \quad$ ((laughter))

In this case, there is not much Jim can say about the gift. It is indeed a desk lamp, and a plain black one. Jim could emphasize how much he needs such a thing, but instead, gift-giver Mike 
jumps in to make a joke about a "fake" function of the lamp (line 74) other than what is obvious about it. By delivering this joke, gift-giver Mike lets Jim off the hook in a sense in terms of needing to do more in his assessment.

Assessing the gift as a giver or onlooker is one way to set up how the gift-recipient should respond, but can also draw attention to the gift-giver rather than the gift-receiver. The purpose of the gifting sequence is "for the gift-recipient," and ostensibly "about the giftrecipient,” but is really more about the relationship between the participants. As such, gift-givers and recipients have an equal stake in the matter. Both are morally compelled to match their assessments. Anything less than a minimally shared sense of the gift and its meaning could be troubling for both, and awkward for onlookers. The relationship is being enacted, but also performed for others (and on camera).

Praising a gift is a way that gift givers can display their assumption (regardless of whether it turns out to be true) that the gift receiver would like the gift. However, praising can also indicate that one thinks highly of one's gift giving abilities or assumes too readily that the gift receiver will like the gift-it can come across as presumptuous. A common way to deal with this dilemma is to claim to have to have wanted the gift for one's self. This adds a note of selflessness (sacrificing a desirable gift for someone else). This choice too, however, can backfire, if it then seems like someone buys a gift for others based on one's own preferences. In excerpt 11, this trouble is circumvented when other family members jump in to construct a gift on behalf of the gift-giver, Beatrice.

\section{Excerpt 11}

79

80

81

82

83

84

85

86

87
Jilly: $\quad$ How'd you part with that [gramma]

Beatrice: [huh?]

Jilly: $\quad$ How did you part with tha:t

Beatrice: ((laughs)) I know I want it myself

Jilly: I $\quad$ bet

Beatrice: $\quad$ That was the hardest part

Janie: (that's the thing) about Christmas

Jack: The hardest part was- was her "oh: I want one I

want one I like that I want one like that" 
Just prior to line 79, Janie, Beatrice’s daughter-in-law, received a scarf for Christmas from Beatrice and Jack. Everyone had been saying it was pretty, when Beatrice's daughter Jilly makes the comment on line 79. This comment emphasizes the goodness of the gift (that it's so pretty Beatrice may not have wanted to part with it). Beatrice catches on in line 82 and acknowledges her role by displaying having wanted the scarf (lines 82, 84), and Janie affirms the response as a typical one at Christmas (line 85). Jack ends the conversation by extending the situation to one that parodies Beatrice coveting various things during shopping (lines 86-87).

Saying a gift is so desirable it may have been hard to part with is one way to co-produce positive gift assessments and make them appear more authentic (more positive assessments verify the assessment of the recipient). This move invokes the intentions of a gift-giver as a way of producing a more detailed positive assessment. But Jack’s remarks (lines 86-87) bring attention to the possibility that this gift might in fact be more desirable to the giver than to the recipient, potentially damaging the authenticity or appropriateness of the assessments under construction. In this case Jack's comment is not taken up and the assessment of the scarf is not treated as problematic.

\section{Dealing with assessment failures}

The previous examples showed some practices which participants employ for managing potential troubles with giving positive and authentic assessments. The next two examples portray how participants deal with the failure to successfully attend to this dilemma. Excerpt 12 is an example of what happens an assessment is not produced quickly or with sufficient enthusiasm.

Excerpt 12

88

89

90

91

92

93

94
Beatrice: You know this is from gramma and grampa right, (0.5) Beatrice: Sam?

Mike: Jilly:

Sam: o:: (.) it's a makeup mirror= =how cute

() 


\begin{tabular}{|c|c|c|}
\hline $\begin{array}{l}95 \\
96\end{array}$ & Mike: & $\begin{array}{l}\text { that's good cuz I just broke yer mirror (1.0) in yer little } \\
\text { black case?= }\end{array}$ \\
\hline 97 & Jilly: & $=$ the mary quant $=$ \\
\hline 98 & Sam: & ((looking puzzled)) \\
\hline 99 & Mike: & $=$ yeah it fell outa the back of the truck (.) you know \\
\hline 100 & & remember how I was talking about the- how everything \\
\hline 101 & & was (.) kyna ((crash sound)) opened the door and it went \\
\hline 102 & & right out the truck (0.5) hit the ground and went to pieces \\
\hline 103 & & $\overline{(.) \mathrm{so}}$ \\
\hline 104 & Sam: & () \\
\hline 105 & Mike: & yeah I know \\
\hline 106 & ((camer & to next scene)) \\
\hline 107 & Beatrice & it magnifies (.) it lights up \\
\hline
\end{tabular}

In this example, Sam is opening a single gift from her grandparents, Jack and Beatrice. Her parents, Mike and Jilly, are also present. Though Sam does not make any negative comment or expression toward the gift, her reaction is not strongly positive either. Her only verbal reactions are stated so softly that they are not picked up by the camera (lines 94, 101). The gift-givers and onlookers display notable work in order to construct the gift as a positive one in response to this delayed and understated response. The gift is set up by Beatrice telling Sam that she (gramma) and grandpa are the gift-givers (line 88). Beatrice seems to pursue recognition of this (line 90), or perhaps a response, from Sam as Sam has opened the gift and ostensibly can see what it is. Mike and Jilly are the first to assess the gift by labeling and praising it (lines 92, 93), followed by Sam's quiet response, during which she is looking down at the gift.

Mike then begins accounting for the gift, though he had no hand in giving it, by emphasizing its functionality or usefulness. He explains that he had recently broken a mirror of hers when it fell out of the back of his truck. Both Mike and Jilly begin collaboratively constructing this explanation (lines 95-97), and when Sam's response is a facial expression of confusion (below), Mike continues describing what happened (lines 99-103).

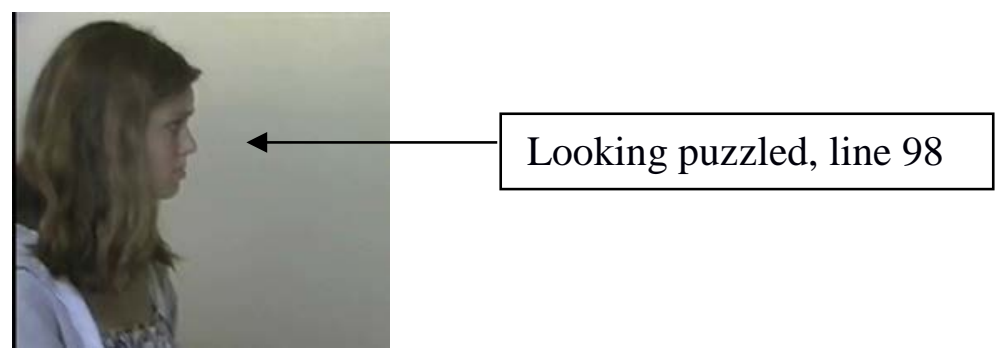


The camera stops recording for a moment, but when it picks up, Sam is still standing by the table where the mirror, in a box, is sitting, and the gift is still having explanations proffered for it (the camera is on the opposite side of the room at this point, so was off for at least as long as it took the person recording to walk around the table and to the other side). Now Beatrice herself, one of the gift-givers, is extolling its virtues (that it magnifies and lights up, line 107). The assessment of the gift, distributed across participants, is partly doing the pursuit of an assessment from Sam. Throughout, Sam does not display enthusiasm, merely looking at the gift without making “excited” assessments or doing much assessment at all (screenshot below) and the family around her responds by in a sense doing that for her.

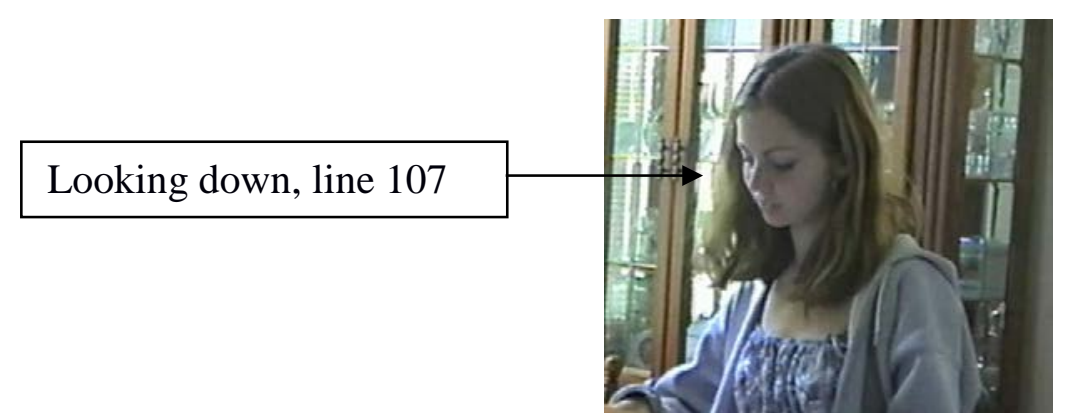

The next excerpt, which features a rare occurrence during which two adults are opening gifts at the same time, contains two simultaneous gift assessment sequences which are then cooriented, both of which contain some troubles around assessing gifts.

\begin{tabular}{|c|c|c|}
\hline \multicolumn{3}{|l|}{ Excerpt 13} \\
\hline 104 & Mike: & Look it's a Dockers (.) belt in [solid] \\
\hline 105 & Beatrice: & [what] did you [ge:t] \\
\hline 106 & Mike: & [wood] \\
\hline 107 & Janie: & [ear]rings? \\
\hline 108 & Beatrice: & $\uparrow o h$ isn't that [ni:ce] \\
\hline 109 & Mike: & [gift] box= \\
\hline 110 & Jilly: & $=[$ yeah $]$ \\
\hline 111 & Janie: & [ye:ah॰] \\
\hline 112 & Beatrice: & {$[($} \\
\hline 113 & Mike: & [who's this from?] \\
\hline 114 & $(1.0)$ & \\
\hline 115 & Janie: & [yea:h] \\
\hline 116 & Jilly: & [mama $]=$ \\
\hline 117 & Mike: & =you [jerk you told me you didn't] get anything= \\
\hline 118 & Janie: & )] \\
\hline
\end{tabular}


Assessments in Gifting 29

119

120

121

122

123

124

125

126

127

128

129
Beatrice:

Jilly:

Beatrice:

(0.5)

Janie:

Jilly:

Janie:

Jilly:

Beatrice:

Jilly:

Janie:
[Jilly (.) I think Jilly]

$=\uparrow \mathrm{I} \quad$ [TOLD you I got a] [bunch of ( $\uparrow$ body) stuff]

[is this from you Jilly,] (.) Jilly

thank you for the pi:n=

$=$ oh isn't it cyu::te

ye:a:h [( )]

[(it's totally cute) $]=$

=what is that $=$

=it's a key chain=

$=$ I have a pin almost just like it

Excerpt 13 begins with two simultaneous conversations. One is between Beatrice and Janie regarding a gift Janie has just opened. The other is between Mike and Jilly regarding a gift Mike has just opened. Jack is seated between both parties, and Jilly is the one holding the camera. Mike comments on his gift, a belt in a wooden box (lines 104, 106, 109). At the same time, Beatrice pursues Janie’s gift (as it was not held up or announced) (line 105). While Beatrice and Janie assess Janie’s gift and work out whom it is from (lines 107, 108, 111, 112, 115, 118, 119, 121), Mike also tries to find out who his gift is from, and discovers it is from Jilly, his wife (lines 113, 116, 117). After Mike unseriously reprimands Jilly (line 117), Beatrice asks Jilly if the gift Janie just opened is from her (121). At this point Janie has now decided that the gift is not earrings, but a pin (line 123). Jilly does not correct Janie’s assumption (line 124), but Beatrice, apparently unsatisfied, questions Jilly explicitly about what the gift is (line 127), and it turns out to be a keychain (line 128). Janie then provides an account of why she thought it was a pin, by explaining that it looks like a pin she has (line 129).

This example contains multiple trouble spots related to assessing the two gifts: one involving ambiguity about the gift, and one involving ambiguity about the gift-giver. In the first case, misidentifying a gift makes assessment particularly sensitive. When Janie’s gift is first (perhaps tentatively) identified as earrings (line 107), Beatrice and Janie agree it is “nice” (lines 108, 111). However, it seems that Janie later revises the identification (if not the assessment) 
because when she directs gratitude toward Jilly, she identifies the gift as a pin (line 123). Jilly does not correct her, instead aligning with the assessment and adding to it (lines 124, 126). This is a way of accepting the compliment that the gift was appreciated. To correct the identification of the gift would perhaps seem ungracious, and would potentially not be upholding the face of the recipient—it would call into question the positive assessment (since it was about something different). Beatrice does this instead (line 127), and it seems to have that effect, since Janie's next turn gives an account for her error (line 129).

Notably, Janie does not at any point actually assess the gift; rather, others assess it, and she agrees with the assessments. In the interaction between Janie and onlooker Beatrice, this is somewhat less problematic because Jilly, the gift-giver, is engaged in a separate conversation. But in the exchange between Jilly and Janie, Jilly ends up praising the gift she herself gave, twice. On the other hand, Janie does express gratitude and attempts to add specificity to her thanks by identifying the gift; unfortunately she misidentifies it. What seems to save the floundering assessment is Janie's last turn. In addition to providing a potential reason for her identification error, it also potentially contains an implicit positive assessment because it compares the gift to something Janie already owns and therefore implies the gift is the sort of thing she might have chosen herself.

The other interaction which is separately in progress before Beatrice signals Jilly in line 121 is between Mike and Jilly. Mike's comment on his gift is more of an identification of what it is than a straightforward assessment, though his directive "look" (line 104) seems to indicate that it is positive enough to look at, perhaps "lookable.” The trouble emerges when Mike asks Jilly whom the gift is from (line 113). Jilly provides the answer (referring to herself) in the third person as "mama" (line 116), an affectionate nickname by which Mike commonly addresses her. Mike sees this as indicating a problem, which is evidenced by his immediate proffering of an 
account (line 117). One on level, Mike could be seen as remiss for thinking Jilly didn’t get him anything because she in fact "told" him she had. Additionally, he may have been remiss because he missed a tag or card that came with the gift (which would have identified it as being from Jilly) though one cannot tell from the data.

On another level, Mike could be seen as remiss for not being able to identify who would get him the gift. A belt (and other clothing-related items) generally requires more intimate knowledge of the person in order to get the correct size. Thus, Mike's account that he hadn't thought Jilly got him something could be a justification for not having correctly identified the giver. Furthermore, this is a many-to-many gifting situation, where all gifts are assumed reciprocal. If Mike didn't think Jilly was getting him anything, it could imply that he didn't get her anything, and that his account is a sort of disclaimer for how Jilly might react later if he didn’t get her a gift. Thus, instead of expressing appreciation, Mike expresses a sort of mock reprimand of Jilly, almost an accusation that she had gotten him a present even though she'd said she wouldn’t or hadn’t. In the dilemma regarding whether to thank Jilly or account for his error(s), Mike chose to give an account. Jilly’s response, in which she raises her voice, nearly shouts one word, and speaks in a higher-pitched tone indicates a sort of chastisement alongside the “I told you” (line 120). This treats both Mike’s error, and the way in which he accounts for it, as problematic.

In this case, Mike does not give a strong positive assessment of his gift and fails to identify the gift-giver as well as to adequately account for this failure. Janie not knowing that Jilly got her gift is not directly treated as an issue, while Mike's similar failure is. Both of the interactions in excerpt 13 feature problems in doing positive assessments and in doing authentic assessments which are particularly tied to relationships and to measures of ambiguity which can be present in the gift-opening enterprise. The lack of Janie’s having announced her gift or 
performed the expected pleasure in receiving it and the lack of Mike’s having performed a positive assessment may have produced a sort of domino effect. Based on the conversation analytic notion that utterances are context-shaped and context-renewing, one can see the troubles participants here display around identifying their gifts and who their gifts are from as being shaped in part by the lack of fully-preferred assessment performances. Subsequent work by Janie to provide the next expected action (thanking the gift-giver) is hindered by a misidentification of the gift—perhaps part of why it was never really assessed—and work by Mike to account for not identifying his gift-giver only gets him deeper and deeper into trouble.

In order to be interactionally preferred and socially successful, assessments must be produced so as to (a) achieve the expected and valued type-conforming features of the event and its sequential production, and (b) intersubjectively orient participant actions and identities toward a shared understanding of the situation and of one another. A dilemma which arises is that the injunction to be positive can compete with the obligation to be authentically positive, revealing the invisible work which is put into assessing gifts. Participants have a number of strategies for dealing with this dilemma, but the difficulty in doing so can cause problems and those problems cause further problems-for instance, in sequence (providing subsequent next actions).

Positive assessments of gifts are strongly preferred in the structure of their production around gift exchanges. However, what "everyone knows" is what everyone must pretend not to know — which is that gifts are socially and relationally loaded, that you cannot react badly to a gift even if it is undesirable, and that gifts must be assumed to have been selected in good faith, with positive intention, and aided by close knowledge of the recipient. These moral facts make assessment tricky when a choice to orient to one is at odds with orienting to another.

\section{Everyone has to lie}


Gifting occasions in the data analyzed herein seemed to follow a recognizable shape involving a sequence of recipient-initiated-assessment+display-of-assessable+other-initiatedassessment/alignment-with-recipient-initiated-assessment+expression-of-gratitude. This sequence was accomplished by multiple participants jointly, through a confluence of verbal, gestural and environmental actions and configurations. Assessments, as the medial focus of giftopening actions, carried an important role in validating the gift, its appropriateness for the recipient, and its meaning to the relationship between giver and recipient.

Two expectations emerged in assessing gifts: "be positive” and "be authentic.” These norms are oriented to in formal gifting occasions through the ways in which people jointly produce responses to gifts. Though the goal of this paper was not to uncover the logic of gift assessment ideals, it seems that these particular ideals would be importantly tied to the formality of the occasion, the presence of an audience and video camera, the closeness of relationships between gift-givers and recipients, and cultural ideologies regarding the importance of giving gifts on certain occasions and what they are meant to represent. Gifting in these instances was about doing celebration by giving people items they would be happy to receive. An unhappy (or even mildly less-than-thrilled) reception of a gift therefore threatens the very reason for the occasion.

Because positive assessments and authentic assessments can exist in tension, participants employed a number of practices managing the possible trouble inherent in gift assessment. One strategy involved producing fairly generic, superficial assessments of a gift's appearance, which fulfilled the demand to give an immediate positive assessment in place of or alongside extreme formulations and happy/surprised facial expressions. Another strategy involved giving more detailed formulations of assessment by including invocations of functional, preferential, and intentional qualities embedded in the gift or its acquisition. 
In order to accomplish actions in discourse, turns must be relevantly designed to match and carry forward prior turns. Sometimes this is an easy thing to do. Most people know the automatic response to "how are you?" is "fine” without having to think about it and without knowing why. But providing the next appropriate turn is not always easy. Some situations are more delicate and complex. It is not simply the case that one can say "express joy and happiness when you open a gift” and leave it at that. In these data gift-recipients worked to produce highly positive assessments quickly and to formulate more detailed assessments thereafter as a way of doing authentic positive assessments of a gift. Gift-givers and onlookers collaborated in building up the meaning of a gift through "mental” explanations of the gift's intentions or well-meant delivery. In doing that which seeks to display the gift's meaning, gifting participants run the risk of undermining the "giving” nature of the occasion (by drawing attention to their own work to construct the gift) as well as revealing the work they and the gift-receiver are doing to cooperatively create the meaning of the gift.

Two examples analyzed featured assessments which were inadequate and created further problems. In one example an assessment was delayed and was not (verbally or nonverbally) produced in a strongly positive or enthusiastic manner. The gift-givers and onlookers attempted to repair this omission by proffering their own assessments, pursuing assessments, and providing information about the valuable qualities of the gift. The assessment was never satisfactorily accomplished and no expression of thanks was caught on film, indicating a serious derailment of the normal order of things in a gifting sequence. In another example, the lack of quick and/or sufficiently positive assessments complicated attempts at next actions such as giving more detailed assessments as well as displaying gratitude. It seems that if the assessment has not met a certain expectation of intensity, it becomes difficult after the fact to authenticate the assessment or to continue the sequence, particularly when ambiguity is involved. Certainly there were other 
examples of ambiguity in the data (where the gift or gift-giver was difficult to identify) but these featured unmarked excited assessments and did not cause trouble.

The troubles involved in assessing gifts pose interesting questions regarding giftexchange occasions as a site of "mundane morality" (Stokoe and Edwards, 2011). The local cultural ideologies governing gifts, their meanings and their sequential exchanges are implicated not just in what people would say about gifting, but also in the actions through which people carry out gifting situations. The practice of gifting cues various contrasting ideologies regarding how to do morally valued identities, actions and relationships.

On one hand, a situated ideal is to be honest and authentic; on the other hand, one is compelled to display only positive reactions to a gift. Furthermore, the interactional choices involved in giving positive assessments could reveal the contrived nature of the response or even signify an unshared meaning for the gift (and potentially for the relationship too). In his "everyone has to lie" paper, Sacks (1975) notes that interactants are compelled to "lie" to others by saying "fine" in response to the howareyou question even if they do not feel fine. A similar principle is at work here; but whereas one is obligated to lie to people in the category of acquaintances and strangers in the greeting ritual, one is obligated to lie to people in the category of close others, such as friends and family, in a gifting situation.

Future research might look at how other assessment-relevant situations might involve similar or different sequences or dilemmas, or how other sorts or different aspects of gifting situations involve sequential and ritualistic elements. An important comparative dimension would come out of analyzing how assessments work in gifting situations across varying cultural settings, as well as considering differences between particular families within a community (as not all family gifting occasions would unfold throughout the U.S. as they did in the data herein). In this work's analysis, home-video-recorded instances of situated interaction around gift- 
exchanges demonstrate recognizable patterns with particular constraints, expectations and purposes. The troubles and dilemmas participants encountered in this paper's analysis may not have frequently erupted into addressable instances, but indicate some of the practical challenges participants face in the everyday interactional accomplishment of morality. 


\section{References}

Areni CS, Kiecker P and Palan KM (1998) Is it better to give than to receive? Exploring gender differences in the meaning of memorable gifts. Psychology and Marketing 15: 81-109.

Belk RW (1988) Possessions and the extended self. Journal of Consumer Research 15: 139 168.

Bergmann J (1998) Introduction: Morality in discourse. Research on Language and Social Interaction 31: 279-294.

Camerer C (1988) Gifts as economic symbols and social symbols. American Journal of Sociology 94: 180-214.

Cheal DJ (1986) The social dimensions of gift behaviour. Journal of Social and Personal Relationships 3: 423-439.

Craig RT (2006) Communication as a practice. In: Shepherd GJ, St. John J and Striphas T(eds) Communication as ...: Perspectives on theory. Thousand Oaks, CA: Sage, pp. 38-47.

Craig RT and Tracy K (1995) Grounded practical theory: The case of intellectual discussion. Communication Theory 5: 248-272.

Fox B (1999) Directions in Research: Language and the Body. Research on Language and Social Interaction 32: 51-59.

Goffman E (1959) The presentation of self in everyday life. New York: Anchor Books.

Goffman E (1967) Interaction ritual: Essays in face-to-face behavior. Garden City, NY: Anchor books.

Goffman E (1974) Frame analysis: An essay on the organization of experience. New York: Harper \& Row.

Goffman E (1981) Forms of talk. Philadelphia: University of Pennsylvania Press. Heath C (2002) Demonstrative suffering: The gestural (re)embodiment of symptoms. Journal 
of Communication 52: 597-617.

Good JS and Beach WA (2005) Opening up gift openings: Birthday parties as situated activity systems. Text 25: 565-593.

Goodwin C (2007) Language, culture, social organization and the material word: Why a five field approach is necessary. Teaching Anthropology: SACC Notes 13: 5-9.

Goodwin C and Goodwin MH (1987) Concurrent operations on talk: Notes on the interactive organization of assessments. Pragmatics 1: 1-54.

Hua Z, Wei L and Yuan Q (2000) The sequential organisation of gift offering and acceptance in Chinese. Journal of Pragmatics 32: 81-103.

Lindström A and Mondada L (2009) Assessments in social interaction: introduction to the special issue. Research on Language and Social Interaction 42: 299-308.

Pomerantz, A. (1984). Agreeing and disagreeing with assessments: Some features of preferred/dispreferred turn shapes. In: Atkinson JM and Heritage J (eds) Structures of social action: Studies in conversation analysis. Cambridge, UK: Cambridge University Press, pp. 57-101.

Rothenbuhler EW (2006) Communication as ritual. In: Shepherd GJ, St. John J and Striphas T (eds) Communication as ...: Perspectives on theory. Thousand Oaks, CA: Sage, pp. 13 22.

Sacks H (1975) Everyone has to lie. In: Blount B and Sanches M (eds) Sociocultural dimensions of language use. New York, NY: Academic press, pp. 57-80.

Stokoe E and Edwards D (2011) Mundane morality and gender in familial neighbour disputes. In: Cromdal and Tholander M (eds) Morality in practice: Exploring childhood, parenthood and schooling in everyday life. London: Equinox, pp..

Tracy K (1995) Action-implicative discourse analysis. Journal of Language and Social 
Assessments in Gifting 39

Psychology 14: 195-215.

Tracy K and Ashcraft C (2001) Crafting policies about controversial values: How wording disputes manage a group dilemma. Journal of Applied Communication Research 29: 297 316.

${ }^{1}$ Including a younger version of the author. 